\title{
Berpikir Kritis: Mendorong Introduksi dan Reformulasi Konsep dalam Psikologi Islam
}

\author{
Ahmad Sulaiman ${ }^{1}, \mathcal{E}$ Nandy Agustin Syakarofath ${ }^{2}$ \\ ${ }^{1}$ College of Education, Psychology and Social Work, Flinders University \\ ${ }^{2}$ Fakultas Psikologi, Universitas Muhammadiyah Malang
}

\begin{abstract}
Islam once triumphed as a great civilization with two main characteristics: an appreciation of science as well as submission to the value of Tawheed. Unfortunately, at present these characteristics seem not to belong to Islam. Various measurement data show that Muslimdominated countries such as Indonesia, have low values in higher-order thinking skills such as creative thinking and problem-solving. As a solution effort, this paper attempts to reintroduce the concept of critical thinking in the body of the current Muslim community. The effort begins by showing how important critical thinking is in Islam, the relevance of Islam and critical thinking and the adaptation of current research in the frame of Islamic Psychology. The main implication of this paper is the importance of seeing the significance of all researchers, both Muslim researchers and outside Muslims, in the process of Islamizing the concept.
\end{abstract}

Keywords: critical thinking; islamic education; islamic psychology

\section{Pendahuluan}

Berpikir kritis dapat diartikan sebagai upaya seseorang untuk memeriksa kebenaran dari suatu informasi menggunakan ketersediaan bukti, logika, dan kesadaran akan bias (Halpern, 1998; Larsson, 2017). Mengingat kondisi sosial yang semakin kompleks dan kemajuan teknologi informasi, mendorong derasnya pertukaran informasi yang belum terverifikasi.

Tidak terverivikasinya pertukaran informasi berdampak terhadap munculnya berbagai persoalan. Menurut Al-Walidah (2017) ketidakmampuan masyarakat untuk mengkritisi kebenaran informasi yang

\footnotetext{
Korespondensi artikel ini dapat dilakukan melalui: ${ }^{1}$ sulaiman_amdamin@outlook.com,

${ }^{2}$ nandi.psikologi@gmail.com
}

diperoleh berdampak terhadap problematika sosial dan chaos dalam berbagai aspek kehidupan manusia. Salah satu contohnya, pada tahun 2015 masyarakat sempat ditimpa kekhawatiran dan resah oleh adanya informasi palsu yang menyebar luas bahwasanya akan terjadi kiamat karena tabrakan yang terjadi antara bumi dan astereoid besar, padahal menurut NASA dari pengamatan yang dilakukan tidak demikian (Syahputra, 2017). Kondisi ini menggambarkan bagaimana kondisi masyarakat kita saat ini. Agar masyarakat dapat objektif menerima informasi yang diperoleh, kritisisme menjadi penting karena akan menghalangi ketergesaan untuk menilai kebenaran data begitu saja, selain itu ia memberi ruang untuk memeriksa dan menolak kebohongan yang mungkin berada di dalamnya. 
Di dalam Islam sendiri untuk memastikan kebenaran akan sebuah informasi dikenal sebuah istilah yang disebut dengan "tabayyun". Menurut Efendi (2016) Tabayyun diartikan dengan sebuah tindakan yang dilakukan untuk mencari kejelasan hakekat atau kebenaran suatu fakta dengan teliti, seksama dan hati-hati. Artinya, dalam Islam setiap manusia dituntut dan didorong untuk senantiasa bersikap hati-hati, tidak mudah mencerna dan mengambil kesimpulan dari setiap informasi yang diperoleh tanpa terlebih dahulu berusaha membuktikan kebenarannya.

Konsep tabayyun yang ada dalam Islam menggambarkan betapa berpikir kritis menjadi perhatian khusus yang kemudian digalakkan sejak awal kemunculannya bahkan hal ini tercantum di dalam kitab suci Alquran. Jafar (2017) menyebutkan bahwa dalam Alquran perintah untuk tabayyun dimaksudkan agar menjaga kemungkinan dampak timbulnya negatif dari penerimaan berita yang tidak selektif, khususnya berita yang terkait kemasyarakatan karena jika tidak berhati-hati akan menimbulkan instabilitas dan disharmoni, bahkan dapat menyebabkan kekacauan dalam suatu kehidupan. Hal ini menunjukkan bahwasanya ada keselarasan antara konsep berpikir kritis dan tabayyun.

Berdasarkan perkembangannya, perhatian Islam terhadap berpikir kritis tidak hanya berhenti menjadi tulisan dalam sebuah ayat saja tetapi juga termanifestasikan dalam setiap tindakan setiap tokoh danilmuwan muslim. Contohnya, pada abad pertengahan muncul tokoh-tokoh intelektual dan sarjana muslim seperti Ibnu Sina, Ibnu Rusyd dan Al Ghazali yang terlahir dari upaya menjawab keresahan yang muncul ditengah-tengah kepentingan politik, faktor geografis dan kebutuhan untuk adaptasi nilai-nilai Islam kepada dunia baru (Bakar, 1986). Bahkan secara bersama-sama tokoh intelektual muslim tersebut melalui saling uji di antaranya, menghasilkan khazanah keilmuan yang hingga sekarang menjadi pondasi bagi dunia modern (Bakar, 1986). Merujuk pada fakta tersebut, memperkuat bahwa berpikir kritis tidak dapat dipisahkan Islam dari sejak kemunculannya hingga saat ini. Bahwasanya berpikir kritis adalah ruh dari setiap gerakan ummat Islam tidak hanya pada suatu momentum tertentu saja tetapi sepanjang masa.

Melihat adanya berbagai kasus terkini terkait penyebaran informasi atau isu yang tidak akurat (fenomena hoax) yang disebabkan oleh derasnya arus informasi di era digital ini dan dampaknya terhadap kehidupan maka peneliti tertarik untuk melakukan penelitian terkait kesadaran seorang muslim terhadap pentingnya berpikir kritis itu sendiri dalam konteks kekinian. Harapannya, informasi yang akan diperoleh dari penelitian ini dapat menjadi masukan bagi setiap individu ataupun sekolah sebagai instansi yang menjadi wadah upaya menumbuhkan berpikir kritis yang dapat diajarkan kepada anak sejak dini sehingga ruh berpikir kritis yang ditekankan oleh Islam tetap terjiwai dalam setiap tindakan seorang muslim.

Berdasarkan uraian tersebut maka tulisan ini bertujuan untuk mendiskusikan lebih dalam terkait tiga ide utama isu terkait konsep berpikir kritis. Pertama, membahas pentingnya berpikir kritis dalam Islam, dimana berpikir kritis ini kemudian menjadi kebutuhan yang utama di dalam dunia muslim dalam konteks kekinian. Kedua, mengkaji hubungan antara Islam dan berpikir kritis yang di mediasi oleh filsafat, yang akan membantu kita mengenali nilai-nilai kritis yang berasal dari khazanah keislaman. Pada bagian terakhir, penyajian hasil penelitian terkini mengenai berpikir kritis dalam bingkai Psikologi islam 
dan langkah strategis ke depan yang dapat dilakukan. Sebelum masuk ke dalam ketiga uraian pokok tersebut, perlu kita pahami tentang pengertian berpikir kritis.

\section{Pembahasan}

\section{Definisi Berpikir Kritis}

Definisi berpikir kritis yang paling luas diterima oleh mayoritas peneliti, baik muslim maupun selain muslim adalah definisi yang dikenalkan oleh Facione (1990). Dalam karya yang dijuluki sebagai 'Laporan Delphi', sebuah proyek penelitian klasik inisiasi Asosiasi Filsafat Amerika (America Philosophical Association), berpikir kritis merujuk pada penilaian bertujuan untuk menghasilkan penafsiran, analisa, evaluasi dan kesimpulan, serta penjelasan atas bukti, konsep, metodologi dan kriteria atau pertimbangan-pertimbangan yang menjadi dasar dari penilaian tadi (Facione, 1990; Nur, Nasution \& Suryanti, 2013). Definisi ini memiliki nilai penting karena ia menggambarkan berpikir kritis sebagai proses kognitif yang sistematis untuk menghasilkan suatu produk berpikir yang dapat dipertanggungjawabkan.

Lebih jauh lagi, Facione (1990) mengkonseptualisasi berpikir kritis sebagai variabel yang terdiri dari dua aspek utama, yaitu aspek (1) keterampilan berpikir kritis atau critical-thinking skills dan (2) sikap kritis atau critical-thinking dispositions. Bila aspek pertama merujuk pada kemampuan untuk menganalisis, mengevaluasi dan menyimpulkan, maka aspek yang kedua merujuk pada tendensi seseorang untuk menggunakan atau berpikir kritis. Berpikir kritis dipandang sulit tercapai bila seseorang hanya memiliki atau menekankan satu di antara kedua aspek di atas (Facione, 1990). Tanpa disposisi berpikir kritis, seseorang akan jarang untuk mengaplikasikan kemampuan berpikir kritisnya, begitu pula sebaliknya, tanpa kemampuan berpikir kritis maka seseorang akan menghasilkan produk pemikiran yang kurang berkualitas.

\section{Berfikir Kritis: Paradigma Barat Vs Islam}

Definisi berpikir kritis yang dikemukakan oleh Facione di tahun 1990 melalui laporan Delphi memberikan suatu konsep yang telah terbukti bermanfaat dalam penelitian secara luas, namun banyak yang menyangsikan kesempurnaannya. Misalnya saja, Moore (2013) menemukan bahwa dalam persepsi pendidik, berpikir kritis memiliki definisi yang begitu luas. Berpikir kritis bisa pula berarti berpikir di luar kotak (kreativitas), menghasilkan ide segar (originalitas) serta kepedulian terhadap masalah-masalah sosial (sensitivitas). Sebagaimana pula menurut Abrami et al. (2008), definisi berpikir kritis yang dominan selama ini memiliki kekurangan karena terlalu kental akan pandangan positivisme. Mereka melihat bahwa berpikir kritis merupakan kekuatan alami manusia yang seringkali tidak dapat secara penuh ditangkap oleh metode pengambilan data paling mutakhir sekalipun. Mereka menyimpulkan bahwa berpikir kritis terlalu sederhana bila dianggap sebagai suatu kemampuan dan sikap dalam menghasilkan produk pikiran yang benar.

Berbeda dengan konsep barat yang fokus hanya kepada pembuktian akan kebenaran sebuah data, berpikir kritis bagi ilmuwan muslim juga memiliki nilai dan tujuan akhir yang ingin dicapai dari proses berfikir, yaitu mencapai iman dan taqwa. Jika konsep barat menafikkan keyakinan akan Tuhan dalam proses berpikir kritis, konsep Islam justru melibatkan. Beberapa peneliti muslim sendiri telah memulai untuk mengkonseptualisasikan berpikir kritis dengan menyerap intisari dan hikmah yang terkandung dalam Alquran serta pemikiran ilmuwan muslim terdahulu 
(Rohmadi, 2018; Endut, Abdullah, Suhaimi, \& Abu Bakar, 2012; Endut \& AS, 2015). Sayangnya, meski konsepsi Islam dinilai penting, namun perlu dilakukan pengujian empiris lebih lanjut untuk mendukung mengingat saat ini tidak banyak diteliti.

Meskipun tidak banyak diteliti, jejak berpikir kritis dalam Islam hingga saat ini dapat dilacak hingga masa-masa terdahulu bahkan sebelum Socrates. Contohnya, kisah Nabi Ibrahim dalam upaya perjalanannya untuk menemukan Tuhan atau kisah-kisah para sahabat dan terkhusus Umar Bin Khatab yang beradu argumen karena perbedaan pendapat dengan Rasul misalnya, menunjukkan betapa Islam hadir untuk mengajak muslim memahami betul mengenai agamanya dan menekankan dialog dalam proses penghayatan keagamaan (Murrad, 2009). Sesuai dengan berkembangnya zaman, tidak hanya fokus akan keyakinan dalam beragama saja tetapi berpikir kritis juga dapat terlihat di dalam berbagai aspek kehidupan dan pengembangan keilmuan seorang muslim. Menurut McCarthy (1980) dalam autobiografinya yang berjudul Al-Munqidh Min Al-Ḍalāl, ilmuwan muslim bernama Al-Ghazali juga telah menekankan berulangkali akan pentingnya pemeriksaan baik berita, pendapat maupun teori-teori ilmu (McCarthy, 1980).

Meskipun terjadi perdebatan, baik konsep berpikir kritis yang dikemukakan oleh barat maupun Islam hingga saat ini belum sepenuhnya mampu menawarkan konsep dasar berpikir kritis yang dapat diterima oleh semua kalangan karena dianggap masing-masing memiliki kelemahan tersendiri. Untuk itu perlu langkah konkret yang diambil untuk mereformulasikan konsep keduanya melalui pengintegrasian konsep.

\section{Urgensi Berpikir Kritis dalam Dunia Islam}

Tidak ada yang bisa menolak betapa pentingnya berpikir kritis. Ia misalnya berpengaruh signifikan terhadap aspek demokrasi dari suatu negara. Demokrasi yang ideal tidak akan tercapai tanpa kemampuan dari masyarakat untuk berdiri di atas informasi akurat disertai deduksi tepat untuk mendukung kebijakan-kebijakan yang mengarah pada peningkatan pembangunan dan kesejahteraan (Giroux, 2004). Bahkan, di tengah-tengah perkembangan teknologi informasi dan menguatnya proses islamisasi dalam berdemokrasi, isu ini seharusnya mendapat perhatian yang paling serius. Beredarnya berita-berita hoax yang viral di tengah masyarakat menjadi benalu bagi demokrasi, dan berpikir kritis dapat menjadi perisai untuk menyeleksi dan menilai kebenaran suatu informasi.

Selain itu, berpikir kritis merupakan jantung dari peradaban ilmu. Ia mengizinkanilmuwan untuk terus berinovasi, mengembangkan temuan-temuan dari studi sebelumnya, melalui koreksi atau bahkan membongkar dan menawarkan orisinalitas yang tidak pernah terbayangkan sebelumnya. Tidak heran karenanya bila perguruan tinggi terkemuka di dunia menjadikan berpikir kritis sebagai salah satu ekspektasi utama dalam proses pendidikan (Larsson, 2017; Philip et al., 2008). Bahkan untuk dianggap sebagai seseorang pelajar, syarat utamanya adalah mampu menilai segala sesuatu yang diterimanya secara kritis.

Berbeda dengan kondisi tersebut, saat ini kondisi pendidikan di Indonesia yang mayoritas penduduknya seorang muslim berbanding terbalik. Alih-alih berfikir kritis, dalam perkembangannya justru mengalami kemandekan berfikir. Kemandekan berfikir ummat Islam saat ini terlihat dari beberapa kasus miskonsepsi yang terjadi, salah satunya adalah miskonsepsi terhadap pandang- 
an Alghazali yang membantah pemikiranpemikiran Ibnu Sina dan pengikutnya terkait kekadiman karena kekhawatiran akan membuat manusia menjadi kurang kritis (Halstead, 2004). Selanjutnya miskonsepsi lain yang menjadi sumbangsih terhadap kemandekan berfikir tersebut adalah adanya pendambaan yang terlalu tinggi kepada ulama serta metode pembelajaran yang berbasis hafalan (Sabki \& Hardaker, 2013).

Kondisi yang berbeda antara di barat dan di Indonesia terkait berpikir kritis sering menjadi masalah tersendiri, khususnya bagi siswa-siswa asal daerah yang menuntut ilmu atau belajar di negaranegara tersebut. Masalah-masalah yang dihadapi oleh pelajar muslim asal Indonesia yang menuntut ilmu di negara tersebut disebabkan oleh berbagai hal, salah satunya adalah kultur belajar reseptif yang menekankan hafalan dan ujian jauh berbeda dengan kultur reproduksi sains yang bertumpu pada kekuatan berargumen dalam menulis (Halstead, 2004). Selanjutnya, juga disebabkan adanya pesimisme dan tuduhan tentang corak praktik pendidikan Islam sendiri yang cenderung memengaruhi gaya berpikir siswanya untuk tunduk tanpa banyak mempertanyakan (Abdullah, 2010).

Agar sejalan dengan fakta sejarah bahwa sebelumnya Islam menjadi katalisator peradaban ilmu yang paling megah dan pernah ada di dunia maka perlu sebuah tindakan serta upaya membongkar tradisi lama yang menyebabkan adanya kemandekan berfikir pada sarjana atau intelektual muslim saat ini mengingat akan kebutuhan zaman yang semakin berkembang, modern, teknologi yang semakin canggih, dan dunia yang kompetitif.

Menariknya tidak hanya Indonesia yang merupakan negara dengan penduduk muslim terbesar, kemandekan berfikir juga dialami oleh negara-negara lainnya di mana muslim menjadi agama mayoritas. Rashid \& Hashim (2008) dan Akkari (2004) menyebutkan hasil sejumlah penelitian bahwa pelajar yang berasal dari negara yang Islam sebagai agama mayoritas rata-rata mengalami kesulitan di dalam berpikir kritis. Negara-negara tersebut antara lain Saudi Arabia (Elyas \& Picard, 2013) dan Maroko (Ennaji, 2005). Bahkan disebutkan bahwa siswa-siswa muslim dianggap kurang kompeten dan tidak seaktif siswasiswa yang berasal dari negara maju (Martin, 2003). Hal ini tentu bertentangan dengan kondisi ideal yang seharusnya terjadi mengingat telah disebutkan sebelumnya bahwa Islam memberikan perhatian penuh terhadap proses berpikir kritis karena dari sanalah kemudian para pemeluk Islam khususnya ilmuwan dan sarjana muslim dapat memperoleh kebenaran.

\section{Penelitian Terkini}

Secara umum, kami melihat terdapat dua macam gerakan penelitian pada tema berpikir kritis dalam Islam dan keduanya dipelopori oleh ilmuwan yang mayoritas berlatar belakang ilmu Psikologi dan Pendidikan. Gerakan yang pertama berfokus pada penggunaan teori-teori yang dikembangkan negara barat untuk dikenakan pada populasi muslim dan menguji efektivitas teori itu pada partisipan yang baru. Sementara gerakan kedua, berupaya mengekstrak konsep berpikir kritis dalam literatur klasik Islam dan Alquran untuk kemudian melahirkan suatu teori baru. Berdasar pendekatan tersebut, gerakan pertama dapat disebut sebagai gerakan kontekstualisasi, sedangkan gerakan kedua disebut gerakan Islamisasi. Meski pendekatan yang dilakukan keduanya berbeda, baik gerakan Kontekstualiasasi maupun Islamisasi memiliki kelebihan dan kekurangan. 
Mereka yang dapat digolongkan pada gerakan kontekstualisasi, adalah peneliti yang secara umum mengadopsi penelitianpenelitan negara barat. Rujukan mereka biasanya kepada dua arus utama pendidikan kritis barat, yaitu arus filsafat (Ennis, 1989; Larsson, 2017; McPeck, 1990) dan arus psikologi (Halpern, 1998; Magno, 2010; Sternberg, 1986). Kedua kutub ahli berpikir kritis ini, memiliki peran penting dalam membangun peradaban barat, secara khusus dalam upaya pendidikan yang demokratis. Beberapa penelitian yang merujuk pada paradigma kontekstualis ini misalkan Dwijananti dan Yulianti (2018), Fakhriyah (2014), dan Rohaeti (2010).

Kelebihan dari gerakan ini adalah mereka memiliki teori yang telah teruji sehingga fungsi dari penelitian mereka yang utama adalah menjustifikasi kekuatan dari teori barat pada subjek penelitian beragama Islam. Peneliti pada golongan ini bermodalkan teori-teori yang telah popular dan telah dikonfirmasi oleh ribuan penelitian sebelumnya. Sehingga, dapat dikatakan bahwa fungsi utama dari usaha mereka adalah promosi dan peningkatan kapasitas berpikir kritis. Tentunya dikarenakan proses adopsi itu, mereka seringkali gagal melihat kelemahan dari teori. Mereka menutup pada kemungkinan bahwa teori yang mereka gunakan tidak kompetibel dengan nafas Islam dan dapat berdampak buruk pada jangka panjang. Sebagaimana banyak dipahami, bahaya utama dari konsep barat adalah kegagapan mereka dalam memelihara nilai-nilai yang luhur, seperti agama dan budaya. Akibatnya, ujung dari pendidikan kritis ini adalah manusia yang ulung namun rendah moral.

Sementara itu, gerakan kedua adalah gerakan penggalian nilai-nilai Islam yang bertemakan berpikir kritis. Berbeda dengan gerakan kontekstualiasi atau replikasi, gerakan Islamisasi merupakan wujud penghar- gaan dan penggalian pada kekayaan intelektual Islam yang terkubur. Para peneliti ini umumnya menjadikan $\mathrm{Al}$ Ghazali sebagai rujukan, dengan meletakkan dialektika yang sang tokoh alami sebagai salah satu metode dalam berpikir kritis (Endut, Abdullah, Suhaimi, \& Abu Bakar, 2012; Endut \& AS, 2015; Zhaffar, Hamzah, \& Razak, 2017). Langkah-langkah dari para peneliti ini bisa dibilang berani, bila mempertimbangkan bagaimana mereka menggali dan menafsirkan kembali khazanah kearifan ilmu Islam. Sayangnya, penelitian mereka masih terbilang baru dan sangat sedikit muslim yang tertarik untuk menggunakan framework penelitian yang autentik ini.

Namun kemudian, meskipun upaya para ilmuwan islamisasi sains ini patut diapresiasi, terdapat beberapa kelemahan yang perlu diselesaikan. Mereka misalnya, kurang mengeksplorasi tokoh-tokoh muslim lain seperti Ibnu Rusyd dan Ibnu Sina sehingga sangat disangsikan apakah teori yang mereka tawarkan adalah Psikologi Islam atau Psikologi Al Ghazali, bila fokus kajian yang mereka lakukan begitu sempit. Belum lagi bila dipahami bahwa tokohtokoh muslim termasuk Al Ghazali memiliki kecenderungan yang mungkin berbeda dengan kecenderungan dari intelektual muslim lain, misalnya dalam epistemologi ilmu yang diyakini. Hal ini menjadikan pengabaian kepada pemikiran tokoh muslim lain yang mungkin penting untuk dilibatkan, baik di generasi yang sama dengan Al Ghazali maupun yang berbeda dengannya.

Juga, hal mendasar yang menjadi kritik keras bagi penelitian mereka adalah kurangnya kemampuan mereka untuk melakukan penelitian dengan standar ilmu yang tinggi. Mereka menghindari penjara keilmuan barat namun menuju padang pasir Islam yang hingga kini belum 
menemukan bentuk konkrit dari kriteria Ilmu. Dampak darinya menjadikan temuan mereka tidak terbangun berdasar bukti yang kuat, yang antara peneliti muslim sendiri enggan sepakat karena keraguan menjustifikasi sesuatu hanya karena pelabelan Islam. Intinya, banyak yang memandang upaya muslim disini seringkali terlihat sebagai gerakan instanisasi ilmu, ketimbang islamisasi ilmu.

Pada sub-bab ini dapat kita tarik kesimpulan, bahwa upaya peneliti muslim untuk membedah tema 'berpikir kritis' telah memberi beberapa sumbangan penting. Namun, kontribusi kedua kelompok penelitian itu dinilai kurang dan memerlukan pengkajian lebih lanjut. Dengan demikian, penelitian berikutnya musti mampu mengintegrasikan konsep-konsep Islam ke dalam framework sains yang mapan, sehingga pembuktian yang ditunjukkan mampu diterima oleh sivitas akademika secara luas, tak hanya ilmuwan muslim yang fokus pada Islamisasi Sains, namun mayoritas muslim peneliti. Demikian juga, peneliti tema 'Berpikir Kritis' musti memahami secara lebih mendalam mengenai konsep berpikir kritis dalam pandangan negara barat. Hal ini penting agar dapat dilakukan kritik yang produktif terhadapnya. Mengingat usaha yang telah dilakukan selama ini seolah tidak melihat berbagai perkembangan konsep berpikir kritis di barat yang mungkin penting bagi proses integrasi atau islamisasi konsep tersebut.

\section{Tantangan bagi Pendidikan Kritis dalam Islam}

Kita juga perlu menyadari bahwa mendorong individu untuk berpikir kritis tidak selamanya dipandang positif oleh sebagian masyarakat muslim, sebab dalam Islam sendiri pada tataran tertentu berpikir kritis menjadi hal yang tabu. Kondisi ini dapat dilihat pada realitas praktik dan pemahaman keagamaan yang ada pada tangan masyarakat awam (grass root society) cenderung terlepas dari pengetahuan akan logika (metodologi) hukum Islam atau istilah lainnya disebut dengan taqlid (Mawardi, 2011). Padahal islam memposisikan akal sebagai elemen penting agar medapatkan sebuah keyakinan yang tinggi dalam mengamalkan sebuah amalan (haqqul yakin), bahkan ia diakui sebagai sumber hukum Islam ketiga sesudah Alquran dan Hadis yang diistilahkan dengan ijtihad (Sidiq, 2007).

Tabunya berpikir kritis dalam kehidupan seorang muslim tidak hanya pada aspek praktik dan pemahaman keagamaan saja namun juga pada aspek muamalah. Menurut Suprayogo (2007) dan Jannah (2015) ada peran kiai yang sangat besar dalam pengambilan keputusan masyarakat di mana ia menjadi tumpuan utama tempat berkonsultasi dalam hampir semua persoalan, seperti masalah keluarga, pendidikan, jodoh, politik, pekerjaan hingga keagamaan. Sayangnya, posisi kiai yang seharusnya menjadi agen perubahan sosial beralih fungsi menjadi dinding pembatas kebebasan berpikir dan bertindak. Hal ini disebabkan adanya dogma kultural bahwa kiai dianggap sebagai orang yang memiliki kekuatan supranatural yang doanya terijabah serta memiliki posisi dan kedudukan yang tinggi sehingga masyarakat harus patuh dan tunduk tanpa ada proses berprikir kritis sebelumnya (Kosim, 2007).

Seperti pada praktik politik misalnya, bagi masyarakat pedesaaan saat pemilihan kepala daerah pengaruh kiai sangat kuat sebagai penentu dasar pemilihan pribadi (Hasanah, 2013), dianggap sebagai pengikat loyalitas umat (Jati, 2012) bahkan dianggap sebagai alat untuk mengumpulkan suara menuju kemenangan, terutama dalam rangka mengerahkan massa (Subiyakto, 2011). Kondisi ini mecerminkan adanya ketidakberdayaan intelektual masyarakat 
awam (grass root society) karena tidak terlatih berpikir kritis sehingga menerima informasi secara pasif.

Berpikir kritis adalah suatu keterampilan yang harus diajarkan kepada individu sejak dini melalui pengetahuan-pengetahuan ataupun disiplin keilmuan agar berhasil dalam kehidupannya di masa mendatang, baik itu sebagai akademisi, profesional, wirausahawan, Pegawai Negeri Sipil (PNS) dan pegawai di perusahaan. Fein (1981) menyebutkan bahwa berpikir kritis pada anak mulai berkembang pada tahun-tahun pra sekolah yaitu usia 5-7 tahun. Hal ini kemudian menjadi penentu kreativitas cara menyelesaikan permasalahan di masa remajanya (Calvery \& Vilson, 2010), serta bagaimana ide-ide berpikirnya berkembang hingga dewasa (RootBreinstein, 2004).

Mengajarkan keterampilan berpikir kritis sejak dini menjadi tanggung jawab bersama, tidak hanya lembaga pendidikan sebagai intitusi tetapi juga perorangan seperti guru dan orang tua. Newman (1996) menyebutkan tugas institusi pendidikan adalah sebagai wadah yang berfungsi mendidik siswanya untuk bernalar dengan baik di dalam segala hal, termasuk menjangkau kebenaran dan memahaminya. Sedangkan pada peran perorangan, guru bertanggung jawab mengembangkan perangkat pembelajaran yang efektif agar peserta didik dapat aktif dan kemampuan berpikirnya berkembang saat mengikuti proses pembelajaran (Windarti, Tjandrakirana \& Widodo, 2018; Anggraini \& Sani, 2015). Selanjutnya, orang tua sebagai lingkungan yang paling dekat dengan anak berperan menumbuhkan dan mengembangkan kreativitas anak dalam menyelesaikan suatu permasalahan melalui proses-proses berpikir kritis (Setia, 2017; Taneri, 2012).

\section{Penutup}

Berdasarkan pemaparan penelitian dan pembahasan dapat disimpulkan bahwa konsep berfikir kritis saat ini dianggap perlu direstrukturasi kembali dengan mempertimbangkan aspek-aspek keislaman dan memadukannya dengan konsep berpikir kritis terakhir yang berkembang di barat. Upaya untuk mereformulasi kembali konsep berpikir kritis tersebut maka ada tiga tema utama yang perlu dilakukan untuk mengkaji kembali literatur dan hasilhasil penelitian terdahulu. Adapun ketiga tema tersebut mencakup, 1) membahas terkait urgensi berpikir kritis dalam islam, 2) penelitian terkini, dan 3) tantangan bagi pendidikan kritis dalam islam.

\section{Daftar Pustaka}

Abdullah, A. K. (2010). Strengthening critical thinking skills among muslim students. Islam and Civilisational Renewal, 1(4), 649 .

Abrami, P. C., Bernard, R. M., Borokhovski, E., Wade, A., Surkes, M. A., Tamim, R., \& Zhang, D. (2008). Instructional interventions affecting critical thinking skills and dispositions: A stage 1 metaanalysis. Review of Educational Research, 78(4), 1102-1134. doi: 10.3102/003465 4308326084

Akkari, A. (2004). Education in the middle east and north africa: The current situation and future challenges. International Education Journal, 5(2), 144-153.

Al-Walidah. (2017). Tabayyun di era generasi millennial. Jurnal Living Hadis, 2(1), 317-3144. doi: 10.4421/livinghadis. 2017.1359

Anggraini, P. \& Sani, A. (2015). The effect of scientific inquiry learning model and 
creative thinking ability on science process skills of student. Journal Pendidikan Fisika, 4(2), 47-54. doi: 10.22611/jpf.v4i2.3238. doi: 10.22611/ jpf. v4i2.3238

Bakar, O. (1986). The meaning and significance of doubt in Al-Ghazzali's philosophy. Islamic Quarterly, 30(1), 31.

Calvery, S. L. \& Vilson, B. J. (2010). The Hanbook of children, media, and development. UK: John Wiley and Sons.

Dwijananti, P., \& Yulianti, D. (2010). Pengembangan kemampuan berpikir kritis mahasiswa melalui pembelajaran problem based instruction pada mata kuliah fisika lingkungan. Jurnal Pendidikan Fisika Indonesia, 6(2). doi: 10. 15294/ jpfi.v6i2.1122

Efendi, E. (2016). Tabayyun dalam jurnalistik. Jurnal Komunika Islamika: Jurnal Komunikasi dan Kajian Islam, 3(3).

Elyas, T., \& Picard, M. (2013). Critiquing of higher education policy in Saudi Arabia: Towards a new neoliberalism. Education, Business and Society: Contemporary Middle Eastern Issues, 6(1), 31-41.

Ennaji, M. (2005). Multilingualism, cultural identity, and education in Morocco. New York: Springer Science \& Business Media.

Endut, M. N. A.-A., Abdullah, W., Suhaimi, W., \& Abu Bakar, Z. (2012). The Islamic element of Al-'Adl in critical thinking: the perception of muslim engineering undergraduates in Malaysia. World Academy of Science, Engineering and Technology (WASET), 758-765.

Endut, M. N. A.-A., \& AS, N. A. (2015). The Islamic epistemological element of AlYaqin in critical thinking. Pertanika Journal of Social Sciences \& Humanities, 23.

Ennis, R. H. (1989). Critical thinking and subject specificity: Clarification and needed research. Educational Researcher, 18(3), 4-10. doi: 10.3102/0013189 X0180 03004

Facione, P. (1990). Critical thinking: A statement of expert consensus for purposes of educational assessment and instruction (The Delphi Report). Diakses dari https://www.researchgate.net/profile/Pe ter_Facione/publication/242279575_Criti cal_Thinking_A_Statement_of_Expert_ Consensus_for_Purposes_of_Education al_Assessment_and_Instruction/links/58 49b94508ae82313e7108de/CriticalThinking-A-Statement-of-ExpertConsensus-for-Purposes-ofEducational-Assessment-andInstruction.pdf

Fakhriyah, F. (2014). Penerapan problem based learning dalam upaya mengembangkan kemampuan berpikir kritis mahasiswa. Jurnal Pendidikan IPA Indonesia, 3(1). 95-101. doi: 10.15294/ jpii.v3i1.2906

Fein, G. G. (1981). Pretend play in childhood: An integrative review. Child Development, 52(4), 1095-1118. doi: 10. $2307 / 1129497$.

Giroux, H. A. (2004). Critical pedagogy and the postmodern/modern divide: Towards a pedagogy of democratization. Teacher Education Quarterly, 31(1), 31-47.

Halpern, D. F. (1998). Teaching critical thinking for transfer across domains: Disposition, skills, structure training, and metacognitive monitoring. American Psychologist, 53(4), 449.

Halstead, M. (2004). An Islamic concept of education. Comparative Education, 40(4), 517-529. doi: 10.1080/030500604200028 4510

Hasanah, I. (2013). Peran Kiai terhadap Pengambilan Keputusan Pemilih dalam Pemilukada Tahun 2013 di Kabupaten 
Pamekasan. diakses dari http://jurnalonline.um.ac.id/data/artikel/artike1987B CB73E871DD267BE4BFA55392BD4F.pdf Jafar, I. (2017). Konsep berita dalam Alquran (implikasinya dalam sistem pemberitaan di media sosial. Jurnalisa, 3(1), 1-15.

Jannah, h. (2015). Kyai, perubahan sosial dan dinamika politik kekuasaan. FIKRAH: Jurnal Ilmu Aqidah dan Studi Keagamaan, 3(1). 157-176. doi: 10.21043/ fikrah.v3i1. 1831

Jati, W. R. (2012). Ulama dan pesantren dalam dinamika politik dan kultur Nahdatul Ulama. Jurnal Studi Islam Ulul Albab, 13(1), 1-15. doi: 10.18860/ ua. v0i0.2377

Kosim, M. (2007). Kyai dan blater (elite lokal dalam masyarakat Madura). Jurnal Karsa, 12(2). 161-167. doi: 10.19105/ karsa.v12i2.139

Larsson, K. (2017). Understanding and teaching critical thinking-A new approach. International Journal of Educational Research, 84, 32-42. doi: 10. 1016/j.ijer.2017.05.004

Magno, C. (2010). The role of metacognitive skills in developing critical thinking. Metacognition and Learning, 5(2), 137-156.

Martin, A. (2003). An experience of teaching in the United Arab Emirates. English Today, 19(2), 49-54.

Mawardi, A. I. (2011). Sisi positif taqlid dalam sejarah perkembangan hukum islam. Islamica, 5(2), 65-67.

McCarthy, R. J. (1980). Freedom and fulfillment: an annotated translation of Al-Ghazālī's al-Munqidh min al-ḍalāl and other relevant works of al-Ghazālī (Vol. 4): NY: Macmillan Reference USA.

McPeck, J. E. (1990). Critical thinking and subject specificity: A reply to Ennis. Educational Researcher, 19(4), 10-12.
Moore, T. (2013). Critical thinking: Seven definitions in search of a concept. Studies in Higher Education, 38(4), 506522.

Murrad, M. (2009). Kisah hidup Umar ibn Khattab. Serambi Ilmu Semesta.

Newman, H. J. (1996). The idea of the university. Yale University Press

Nur, M., Nasution, \& Suryanti, J. (2013). Keterampilan proses sains dan berpikir kritis. Surabaya: Universitas Negeri Surabaya

Philip, C. A., Robert, M. B., Evgueni, B., Anne, W., Michael, A. S., Rana, T., \& Dai, Z. (2008). Instructional interventions affecting critical thinking skills and dispositions: A stage 1 metaanalysis. Review of Educational Research, 78(4), 1102-1134. doi: 10.3102/003465430 8326084

Rashid, R. A., \& Hashim, R. A. (2008). The Relationship Between Critical Thinking and Language Proficiency of Malaysian Undergraduates. Diakses dari http://ro.ecu.edu.au/cgi/viewcontent.cgi ?article $=1035 \&$ context $=$ ceducom

Rohaeti, E. E. (2010). Critical and creative mathematical thinking of Junior High School student. Educationist Journal, 4(2), 99-106.

Rohmadi, S. H. (2018). Pengembangan berpikir kritis (crititcal thinking) dalam Alquran. Jurnal Psikologi Islam, 5(1), 2736.

Root-Bernstein, R. S., \& Root-Bernstein, M. M. (2004). Artictic scientists and scientific artists: The link between polymathy and creativity. https: //www. researchgate.net/publication/232558153_ Artistic_Scientists_and_Scientific_Artist s_The_Link_Between_Polymathy_and_ Creativity. doi: 10.1037/106 92-008

Sabki, A. I. A., \& Hardaker, G. (2013). The 
madrasah concept of Islamic pedagogy. Educational Review, 65(3), 342-356. doi: 10.1080/00131911.2012.668873.

Setia, I. (2017). Peran orang tua dalam menumbuhkembangkan kreativitas anak. Atthulab: Islamic Religion Teaching and Learning Journal, 2(1), 83-96.

Sidiq. (2007). Aktivitas akal dalam pembuktian wahyu. Jurnal Hunafa, 4(1), 41-48.

Sternberg, R. J. (1986). Critical thinking: Its nature, measurement, and improvement. Washington, DC: National Inst. of Education

Subiyakto, R. (2011). Panggung politik kiai di era pemilukada. Jurnal Ilmu Syari'ah Dan Hukum, 45(22), 1564-1579.

Suprayogo, I. (2010). Kiyai dan Politik membaca citra politik kiyai. Malang: UINMalang Press.
Syahputra, H. (2017). Melepas hoax dari genggaman kita. Dalam A.Wahyudi, \& M. Suantari, Melawan Hoax di Media Sosial dan Media Massa (hal. 125-126). Yogyakarta: Trust Media Publishing.

Taneri, P. O. (2012). Roles of parents in enhancing children's creative thingking skills. International Journal of Human Sciences. 9(2), 91-108.

Windarti, Tjandrakirana \& Widodo. (2013). Melatih keterampilan berpikir kritis menggunakan metode pembelajaran penemuan terbimbing (guided discovery) pada siswa SMP. Jurnal Penelitian Pendidikan Sains, 3(1), 274-281.

Zhaffar, N. M., Hamzah, M. I., \& Razak, K. A. (2017). Elemen pemikiran kritis dalam konteks kemahiran berpikir aras tinggi. Asean Comparative Education Research Journal on Islam And Civilization, 1(2), 92-101. 